\title{
Mangrove restoration without planting
}

\author{
Babak Kamali, Roslan Hashim
}

Tropical shorelines are often occupied by stretches of mangrove

forests. Despite the wide range of ecological and socio-economic

benefits provided by mangrove ecosystem (Lewis, 2005; Bosire

et al., 2008), over the past decades the mangrove hasbecomea plant

in peril. The area of the world's mangrove forests has decreased by $35 \%$ during the last two decades of the 20th century (Valiela et al.,

2001). Vast areas of mangrove forests have been cleared for urban

development, industrialisation, agricultural land reclamation, timber

and charcoal production and shrimp farming. Mangrove forests

are still declining at such an alarming rate, particularly in developing

countries, that these ecosystems may completely disappear

within the next 100 years (Duke et al., 2007).

Governments and local stakeholders eventually realised the

true value of mangrove ecosystems and consequently have made

efforts to protect and restore these unique ecosystems. However, it

seems that in this context restoration means planting/replanting. Apparently, ad hoc attempts that have been made in the past due to the lack of knowledge and experience are still common. In reviewing

attempts to restore mangrove ecosystems, it emerges that

restoration projects are not always successful in achieving their

goals (Elster, 2000; Lewis, 2005). Failure of an attempt to restore

mangrove could cost thousands to millions of dollars. For instance, the outcome of two decades of immense efforts to restore mangrove forests in Philippines is only 10-20\% long-term survival rates at a cost of millions of dollars because of inappropriate species and site selection (Primavera and Esteban, 2008; Samson and Rollon, 2008). Although there are many restoration projects around the world, only a small number have been planned or studied by ecologists and other scientists (Kentula, 2000). Hence, there is often a lack of documentation and realistic expectations, especially when the effort fails. This makes it difficult to review and determine the reasons for success or failure of most of restoration and reforestation efforts. However, the absence of ecological planning and realistic well-defined goals (Bosire et al., 2008; Lewis, 2000) could be one of the main reasons for failure.

Lewis (2005) states that restoration or rehabilitation may be recommended when an ecosystem has been altered to such an 
extent that it can no longer self-correct or self-renew. The causes of degradation, where the natural recovery process has not occurred, should be identified and removed as the first step in restoration or rehabilitation process. Mangroves may recover naturally if the morphological and hydrological features of the habitat were not alerted (Martinuzzi et al., 2009). Mangroves are sensitive to inundation depth and period that inappropriate inundation regime can affect their growth and survivorship, especially during the establishment period (McKee, 1995; Kitaya et al., 2002; He et al., 2007).

Lewis and Streever (2000) suggest that after restoring the suitable hydrologic regime mangrove would only be planted when natural regeneration had not occurred, perhaps due to propagules limitation. The term propagules limitation explains the situation in which natural waterborne propagules are not available in a restoration area (Lewis, 2005). In this case planting mangrove seedlings/propagules is the only, or in fact the last, option to restore a mangrove ecosystem.

On exposed shorelines, wave action and erosion are among the most important factors that affect mangrove seedlings survivorship. Fringe mangrove seedlings can be uprooted and washed away by strong waves and currents. Furthermore, erosion can alter the morphology of the site and hence the inundation regime. Low wave-energy climate which is suitable for mangrove to establish its roots in the substrate could be provided by a barrier (i.e. coastal structure). In practice, however, such a combination of coastal structure and restoration work is not common perhaps because the restoration projects are not often include coastal engineers.

This paper aims to describe and discuss the results of an ecological engineering approach to mangrove restoration on an exposed shoreline which suffers from erosion and degradation.

\section{Materials and methods}

Study area

In 2008, a restoration project was commenced in Sungai Haji Dorani (SHD) on the west coast of Peninsular Malaysia by a group of researchers in the Institute of Ocean and Earth Sciences, University of Malaya. The restoration site is located in a barren area of intertidal zone (03.38_N and 101.00_E), which was previously occupied by a fringing mangrove forest, next to a degraded mangrove area. The tidal regime is semi-diurnal with amaximum tidal range of $3.2 \mathrm{~m}$. The foreshore has a gentle slope of about $1 \%$. The site is frequently exposed to direct waves from SW (during southwest monsoon) and WNW (during northeast monsoon), with the significant wave height lower than $1 \mathrm{~m}$ about $89 \%$ of the time. The significant offshore wave height with a return period of 10 years is about $1.50 \mathrm{~m}$ according to the Malaysian Metrological Department. 
The SHD beach is predominantly covered by greenish-grey mud deposits composed of $22 \%$ clay, $56 \%$ silt, $17 \%$ fine sand, and $5 \%$ organic matter on average. The $\mathrm{pH}$ value of soil water ranges from $6.8 \pm 0.1$ to $7.1 \pm 0.1$. Mean salinity ranges from 23.9 to 36.8 ppt.

The muddy beach of SHD used to be occupied by mangroves, but over the past decades mangroves have declined and the beach has undergone severe degradation and recession. In 1977, a sea dyke was constructed along the SHD beach by Department of Irrigation and Drainage (DID) in order to avert tidal flooding and reclaim land. These coastal structures (in Southeast Asia often called 'coastal bunds') are very common in the west coast of Peninsular Malaysia. Since 1950s, based on a national policy to develop coastal areas, mangrove swamps have been converted to agricultural land, especially oil palm cultivation, along the west coast of Peninsular Malaysia. DID constructed earth dykes to protect these agricultural areas from tidal inundation while a strip of mangroves were left between the dykes and the sea as a buffer zone to reduce wave energy (Othman, 1994). Apparently, mangroves were not considered as productive or important unique ecosystems. Consequently, large areas of mangroves were cleared simply because their true value was not known to the managers and policy makers. A narrow strip of mangroves was left to protect the dyke from erosion. Ironically, mangroves (in front of the dykes) have vanished.

In SHD, the mangrove ecosystem was disturbed too much by the presence of the dyke that broke the link between the mangroves and the backshore. As a result, the mangrove area has been squeezed between the dyke from the landward side and the wave action from the seaward side (Hashim et al., 2010). The elevation of themudflathas decreased during the past decades. While the actual reason is not known, this is a cause for more degradation of the existing mangroves. It has been observed that the fringe mangroves have fallen down because of erosion that weakened the supporting soil and the root structure. This affects mangroves margin position that mangroves tend to retreat landward to higher elevations to maintain their favourable hydrology (Gilman et al., 2008).

Calm area, stable substrate, and correct hydrology have a pivotal role in mangrove establishment. A calm area and stable substrate could be provided by intervention of a detached breakwater which could dissipate or reduce the incident wave energy. The approach used in the SHD study was well described by Hashim et al. (2010). Therefore, we briefly review the method in this paper.

Integrated approach to restore mangrove habitat

The approach was called integrated because of using both hard 
(i.e. breakwater) and soft (i.e. mangrove replanting) techniques to rehabilitate the beach. A breakwater was constructed seaward the restoration area to reduce the wave energy reaching the shore in order to shelter the transplanted mangroves and enhance deposition of sediments. Sedimentation was expected to build up the sea floor elevation in order to provide the appropriate hydrology (datum recovery).

On the basis of a desk study, a detached breakwater was designed composed of three segments separated by $5 \mathrm{~m}$ gaps that allow water circulation (see Fig. 1). This $90 \mathrm{~m}$ long low crested structure shelters an area of about $7000 \mathrm{~m} 2$. The structure is a homogenous rubblemoundbuilt of quarried rock. The construction was completed in July 2008 at a cost of US $\$ 42,850$.

Avicennia marina seedlings collected from a healthy natural habitat were planted in coir logs. Coir logs are made from coconut fibre compressed and encased in polypropylene netting; each coir log was $3 \mathrm{~m}$ in length and $0.3 \mathrm{~m}$ in diameter. After six months of being nurtured in the nursery the coir logs were moved to the site for transplantation (Hashim et al., 2010). A. marina was selected for transplantation because it is the dominant species in the study area and has a better flood tolerance (He et al., 2007) suiting the eroded coast of SHD. The initial planting (inclusive of coir logs production and nursery set up, transplanting, and monitoring) was carried out at a total cost of US $\$ 37,150$ (US $\$ 61,916$ ha-1 as the planting area was $0.6 \mathrm{ha})$.

For setting goals in ecological restoration, Cairns (2000) emphasised that the effort would not be successful without the approval of human society. He used the term socially feasible to explain that the public support is as essential as technically feasible and scientifically valid goals for a successful restoration. The public and authorities often demand to see rapid progress, because they have an aversion to waiting a long time (e.g. 3-5 years) to see the long-term outcomes. During this project through workshops, which were open to the public, we tried to communicate with and convince local villagers to support the project. Fortunately, they were interested in mangrove restoration, particularly because of fisheries enhancement function of mangroves.

Full text available at :

http://ac.els-cdn.com/S0925857410003198/1-s2.0-S0925857410003198-main.pdf?_tid=2dc77344-66e4-11e38582-00000aab0f6b\&acdnat $=1387261775$ 89f95b85ed06e928a0a432f227ca09be

www.sciencedirect.com/science/article/pii/S0925857410003198 